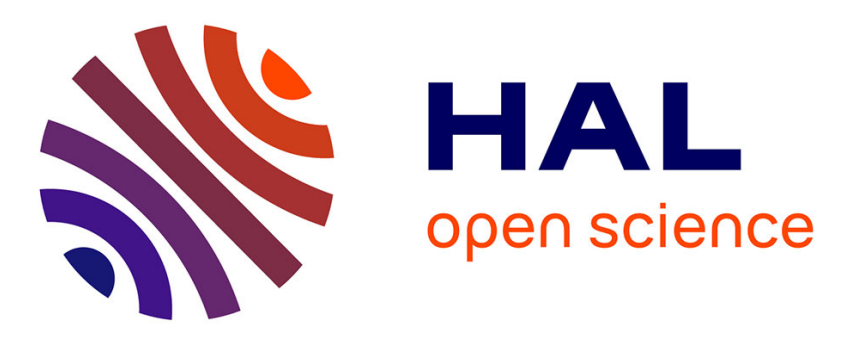

\title{
Characterization of heat sources due to deformation in unfilled natural rubber
}

Jose Ricardo Samaca Martinez, Jean-Benoit Le Cam, Xavier Balandraud, Evelyne Toussaint, Julien Caillard

\section{- To cite this version:}

Jose Ricardo Samaca Martinez, Jean-Benoit Le Cam, Xavier Balandraud, Evelyne Toussaint, Julien Caillard. Characterization of heat sources due to deformation in unfilled natural rubber. European Conference on Constitutive Models for Rubber VIII, Jun 2013, San Sebastian, Spain. hal-01136534

\author{
HAL Id: hal-01136534 \\ https://hal.science/hal-01136534
}

Submitted on 18 May 2020

HAL is a multi-disciplinary open access archive for the deposit and dissemination of scientific research documents, whether they are published or not. The documents may come from teaching and research institutions in France or abroad, or from public or private research centers.
L'archive ouverte pluridisciplinaire HAL, est destinée au dépôt et à la diffusion de documents scientifiques de niveau recherche, publiés ou non, émanant des établissements d'enseignement et de recherche français ou étrangers, des laboratoires publics ou privés. 


\title{
Characterization of heat sources due to deformation in unfilled natural rubber
}

\author{
J.R. Samaca Martinez \\ Clermont Université, Université Blaise Pascal, Institut Français de Mécanique Avancée, \\ Institut Pascal, Clermont-Ferrand, France \\ CNRS, UMR 6602, Université Blaise Pascal, Institut Pascal, Aubière, France \\ Manufacture Française de Pneumatiques Michelin, CERL Ladoux, Clermont-Ferrand, France
}

J.-B. Le Cam

Université De Rennes 1, Larmaur ERL CNRS 6274, Campus de Beaulieu, Rennes, France

\author{
X. Balandraud \& E. Toussaint \\ Clermont Université, Université Blaise Pascal, Institut Français de Mécanique Avancée, \\ Institut Pascal, Clermont-Ferrand, France \\ CNRS, UMR 6602, Université Blaise Pascal, Institut Pascal, Aubière, France
}

J. Caillard

Manufacture Française de Pneumatiques Michelin, CERL Ladoux, Clermont-Ferrand, France

\begin{abstract}
This paper deals with the calorimetric analysis of deformation processes in natural rubber. Infrared thermography is first used to measure the temperature evolution of specimens under quasi-static uniaxial loading at ambient temperature. Then the heat sources produced or absorbed by the material due to deformation processes are deduced from the temperature variations by using the heat diffusion equation. Heat sources are a more relevant quantity than temperature variations because the latter are influenced by the heat exchanges with the outside environment of the specimen. Different results are obtained from cyclic tests and relaxation tests. First, the heat source due to thermoelastic (entropic) coupling increases with the stretch ratio at constant stretch rate. Second, no mechanical dissipation (intrinsic dissipation) is detected during the material deformation. Third, strain-induced crystallization leads to significant heat production, whereas the melting of crystallites absorbs the same heat quantity with different kinetics. This difference in kinetics explains the hysteresis loop observed in terms of the strain-stress relationship. Finally, relaxation tests on unloading show that crystallite melting does not systematically occur instantaneously.
\end{abstract}

\section{INTRODUCTION}

The physical mechanisms involved in the deformation of natural rubber are numerous and are still the object of keen scientific debate, among them viscosity, strain-induced crystallization and crystallite melting, cavitation, as well as energetic and entropic effects on the thermomechanical response. To investigate these physical deformation processes, several experimental techniques have been used, including X-ray diffraction (Katz 1925, Toki, Fujimaki, \& Okuyama 2000), X-ray microtomography (Legorju-Jago 2007), dilatometry (Ramier, Chazeau, Gauthier, Stelandre, Guy, \& PeuvrelDisdier 2007) and classic mechanical tests such as stress relaxation and cyclic tests. Any deformation process induces heat production or absorption that can be detectable or analyzable with the abovementioned techniques. For this purpose, infrared (IR) thermography seems to be an appropriate technique to detect heat sources from measured temperature variations. Indeed, IR thermography has proved over the last twenty years to be a relevant technique to provide information of importance on the deformation processes in materials such as steels, aluminium alloys and composites. Moreover, various studies previously carried out by Chrysochoos and co-workers have shown that heat sources produced by the material itself were more relevant than temperatures when analyzing various phenomena such as Luderís bands (Chrysochoos \& Louche 2001), fatigue (Berthel, Wattrisse, Chrysochoos, \& Galtier 2007) or strain localization (Wattrisse, Chrysochoos, Muracciole, \& Némoz-Gaillard 2001). The main 
reason is that the temperature field is influenced by heat conduction as well as heat exchanges with the ambient air and the grips of the testing machine used. In rubbery materials, which undergo large deformations, only two studies have recently been carried out to develop motion compensation techniques in the case of heterogeneous tests (Pottier, Moutrille, Le Cam, Balandraud, \& Grédiac 2009, Toussaint, Balandraud, Le Cam, \& Grédiac 2012). These studies focused on the numerical posttreatment of temperature fields, and were not dedicated to the analysis of the deformation processes. The present paper aims therefore at applying quantitative calorimetry to characterize and to analyze the thermomechanical behaviour of natural rubber under homogeneous uniaxial tensile tests, at ambient temperature.

The first section describes briefly the thermomechanical framework used to assess heat sources from temperature fields measured at the specimen surface. The second section describes the experimental setup, in terms of the material used, loading conditions and IR measurement technique. The third section presents the results obtained and a discussion of the deformation processes.

\section{THERMOMECHANICAL FRAMEWORK}

Temperature fields measured at the flat surface of a specimen by an IR camera are $2 \mathrm{D}$, i.e. bidimensional. As the tests performed are assumed to be homogeneous in terms of strain and stress, and as rubbers have a very low thermal diffusivity, one observes nearly homogeneous temperature fields. So a '0D' approach can be developed. However, this approach is not completely detailed in this paper, the interested reader is referred to (Samaca Martinez, Le Cam, Balandraud, \& Toussaint 2013) for further information.

Let us start from the 3D formulation of the heat diffusion equation. In a thermomechanical framework (Nguyen, Germain, \& Suquet 1983), the local state axiom is assumed (Boccara 1968).

$$
\begin{aligned}
& \rho C_{E, V_{k}} \dot{T}-\operatorname{div}(K \operatorname{grad} T)-r \\
& =\underbrace{d_{1}+\rho T \frac{\partial^{2} \Psi}{\partial T \partial E} \dot{E}+\rho T \frac{\partial^{2} \Psi}{\partial T \partial V_{k}} \dot{V}_{k}}_{S}
\end{aligned}
$$

By using thin specimens, the problem can be considered as bidimensional. At a given point $(x, y)$ on the surface, the temperature is thus nearly homogeneous through the thickness. In fact, a small temperature gradient exists close to the specimen faces due to the heat exchange by convection with the air, but the surface temperature can be considered as very close to the mean temperature in the thickness. Then, by integrating the heat diffusion equation (1) over the specimen thickness and defining the mean thermal disequilibrium through the thickness between the specimen and its surroundings by $\theta(x, y)$, the following bidimensional formulation of the heat diffusion equation is obtained:

$\rho C_{F, V_{h}}\left(\dot{\theta}+\frac{\theta}{\tau_{2 D}}\right)-\operatorname{div}_{2 D}\left(K_{2 D} \operatorname{grad}_{2 D} \theta\right)=s$

where $\tau_{2 D}$ is a time constant characterizing the heat exchanges by convection with the air at the specimen surface. It is assumed to be the same at any point $(x, y)$ of the specimen. It can be defined as follows (see Ref. (Chrysochoos \& Louche 2000)):

$\tau_{2 D}=\frac{e \rho C_{E, V_{k}}}{2 h}$

where $e$ is the specimen thickness and $h$ a convection coefficient. In practice, the constant $\tau_{2 D}$ is experimentally assessed by identification from a simple test of natural return to room temperature.

The $2 \mathrm{D}$ equation (2) can be reduced to a " $0 \mathrm{D}$ " formulation in the case of heat source fields which are homogeneous in the specimen (Chrysochoos 1995). In the present study, this approach is relevant because the tests are assumed to be homogeneous in terms of strain and stress. Moreover, rubbers have a very low thermal diffusivity, which leads to nearly homogeneous temperature fields. In such a case, the heat diffusion equation can be rewritten (Chrysochoos 1995):

$\rho C_{E, V_{k}}\left(\dot{\theta}+\frac{\theta}{\tau}\right)=s$

where $\tau\left(=\tau_{0 D} \approx \tau_{2 D}\right)$ is a time constant characterizing the heat exchanges between the specimen and its environment, i.e. the ambient air and the jaws of the testing machine. It can be noted that $\tau$ must be measured for each testing configuration (material, specimen geometry, environment in terms of ambient air and jaws of the testing machine).

Some comments can be added concerning tests that are performed on rubber materials. Large deformations lead to a variation in the specimen thickness, leading also to a change in the value of $\tau$ (see equation (3)). In this case, a linear expression of $\tau(\lambda)$ (see equation (5)) has been found experimentally, where $\tau(\lambda)$ is expressed in seconds (see (Samaca Martinez, Le Cam, Balandraud, \& Toussaint 2013)). 
$\tau(\lambda)=40.48-3.25 \lambda$

Let us conclude with some considerations on units. The heat source $s$ is expressed in $\mathrm{Wm}^{-3}$. However, it is generally useful to divide this quantity by $\rho C_{E, V_{k}}$ :

$\dot{\theta}+\frac{\theta}{\tau}=\frac{s}{\rho C_{E, V_{k}}}$

The quantity $s / \rho C_{E, V_{k}}$ is expressed in ${ }^{\circ} \mathrm{C} / s$ (corresponding to the temperature rate that would be obtained in an adiabatic case, i.e. for an infinite $\tau$ ). In the rest of the paper, the term "heat source" will also be used for this quantity $s / \rho C_{E, V_{k}}$.

Note finally that throughout the document, the term "heat" must be distinguished from "heat source". The heat is the temporal integration of the heat sources. It is expressed in $J . m^{-3}$ (in ${ }^{\circ} C$ when divided by $\left.\rho C_{E, V_{k}}\right)$.

\section{EXPERIMENTAL SETUP}

\subsection{Material and specimens}

The material considered here is an unfilled natural rubber NR (supplied by Michelin Co.). Its material formulation is given in Table 1. This material was chosen in order to analyze the thermal response of the macromolecular network without interaction between the rubber matrix and the fillers. It should be noted that this rubber formulation leads to stress-induced crystallization (Trabelsi, Albouy, \& Rault 2003, Marchal 2006). In particular, the characteristic stretch ratios at which crystallization and crystallite melting occur are denoted by $\lambda_{c}$ and $\lambda_{m}$ and are close to 4 and 3 , respectively.

The sample geometry is a typical dumbbell form sample, with a $5 \mathrm{~mm}$ width, $10 \mathrm{~mm}$ height and $1.4 \mathrm{~mm}$ thickness. Its width was chosen to ensure that the strain and stress fields are as homogeneous as possible, thus corresponding to a uniaxial tension test state.

Table 1. Chemical composition in parts per hundred rubber (phr).

\begin{tabular}{lc}
\hline Ingredient & Quantity \\
\hline Natural rubber NR & 100 \\
Carbon black & 0 \\
Antioxidant 6PPD & 1.9 \\
Stearic acid & 2 \\
Zinc oxide ZnO & 2.5 \\
Accelerator CBS & 1.6 \\
Sulfur solution 2H & 1.6 \\
\hline
\end{tabular}

\subsection{Loading conditions}

The tests were performed using an Instron 5543 uniaxial testing machine with a capacity of $50 \mathrm{~N}$. Two types of tests were carried out under imposed displacement and triangular signal (see Fig. 1):

- Cyclic test-It is composed of four sets of three cycles, with four increasing maximum stretch ratios: $\lambda_{1}=2, \lambda_{2}=5, \lambda_{3}=6$ and $\lambda_{4}=7.5$, as shown in Figure 1(a) $\lambda_{1}$ was chosen inferior to the crystallization stretch ratio $\lambda_{c}, \lambda_{2}$ was close to $\lambda_{c}$ and finally $\lambda_{3}$ and $\lambda_{4}$ were superior to $\lambda_{c}$. The tests were carried out at a constant loading rate, $\pm 300 \mathrm{~mm} / \mathrm{min}$, i.e. at nominal strain rate $\pm 0.5 \mathrm{~s}^{-1}$.

- Relaxation test 1 -This consists of one mechanical cycle at $\pm 300 \mathrm{~mm} / \mathrm{min}$, including pauses of $30 s$ at the four previously mentioned stretch ratios, during loading and unloading, as shown in Figure 1(a).

These tests are usually applied for the mechanical characterization of rubber, in order to investigate stress softening, i.e. the Mullins effect (Mullins 1948), loading rate effects, i.e. viscosity effects, crystallization phenomena and cyclic damage.

\subsection{Temperature measurement and post- processing}

Temperature measurements were performed using a Cedip Jade III-MWIR infrared camera. Temperature variations were measured at $147 \mathrm{~Hz}$ in a small square zone of 5 pixels $\times 5$ pixels located at the centre of the specimen during the test. A movement compensation technique was used to track this small zone during the test (see (Samaca Martinez, Le Cam, Balandraud, \& Toussaint 2013)).

From a post-processing point of view, the heat sources are obtained from the temperature variations by using the left-hand part of equation (6). The temporal derivate is obtained by finite differences. In practice, temporal filtering was used in order to have a better resolution of the source measurement. Of course, this filtering slightly penalized the temporal resolution of the heat

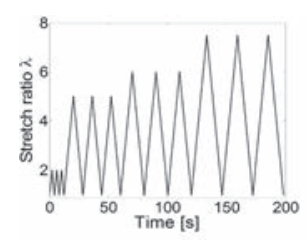

(a) Cyclic test

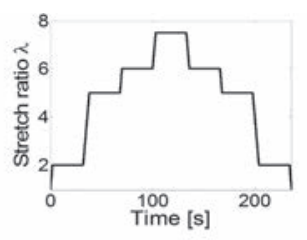

(b) Loading-unloading test with relaxation steps
Figure 1. The two mechanical loading conditions. 
source measurement: for the present study, the minimum duration between two independent values is equal to $0.08 s$ (compared with the temporal resolution of the temperature measurement, which is equal to $1 / 147=0.0068 s$ ).

\section{RESULTS}

Temperature variation is not the most relevant quantity to analyze the thermomechanical response of rubbers. Indeed, the temperature variation depends on the level of adiabaticity of the test i.e on the heat exchanges with the environment of the specimen in $0 \mathrm{D}$. This is the reason why the material behaviour is analyzed in terms of heat source versus time or stretch ratio, for the two types of test presented above.

\subsection{Cyclic test}

Figure 2 gives the corresponding heat source produced by the material itself during the mechanical loading. Some comments can be made concerning this result. First, the heat sources are positive during the loading phases, and negative during the unloading phases. Second, a dissymmetry is observed between loading and unloading.

In order to analyze the results more precisely, Figures 3-6 give the heat source as a function of the

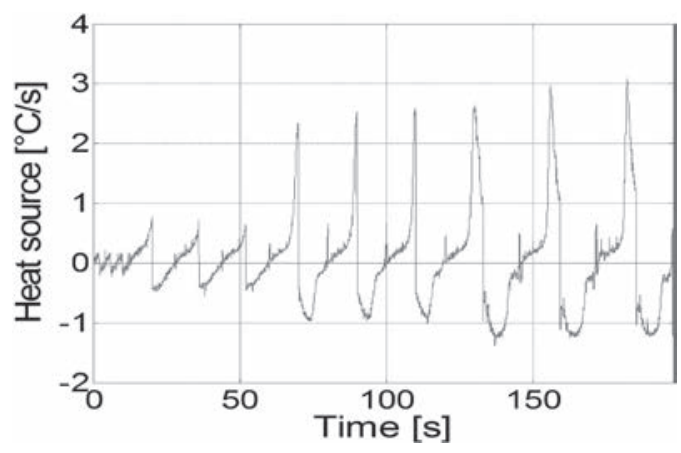

Figure 2. Evolution of the heat sources for the four increasing maximum stretch ratios.
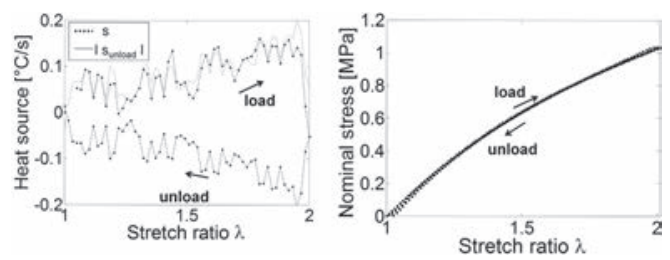

Figure 3. First cycle at $\lambda_{1}=2$. Left: heat source versus stretch ratio. Right: strain-stress curves.
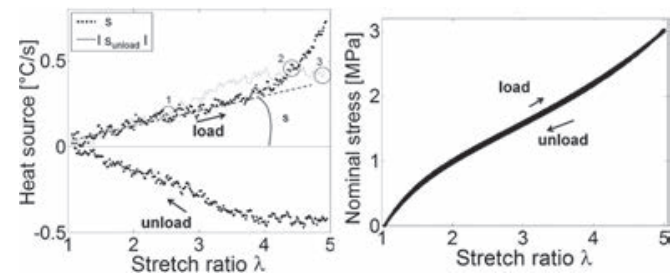

Figure 4. First cycle at $\lambda_{2}=5$. Left: heat source versus stretch ratio. Right: strain-stress curves.
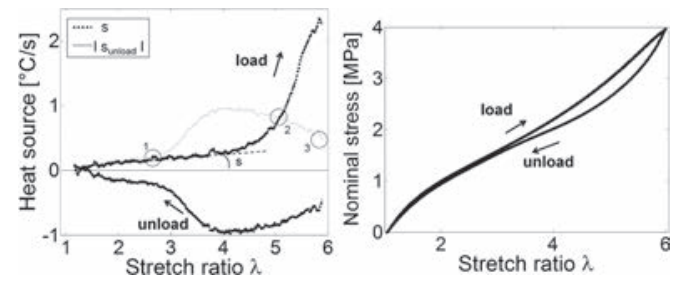

Figure 5. First cycle at $\lambda_{3}=6$. Left: heat source versus stretch ratio. Right: strain-stress curves.
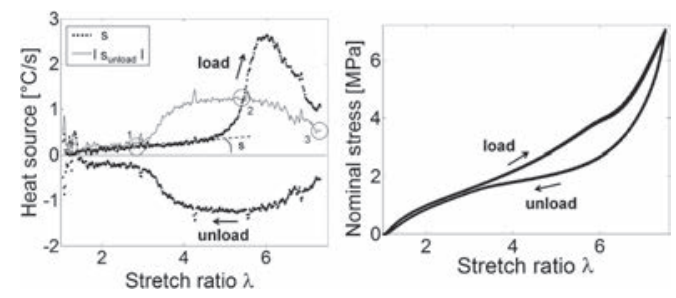

Figure 6. First cycle at $\lambda_{4}=7.5$. Left: heat source versus stretch ratio. Right: strain-stress curves.

stretch ratio during the first cycle of each set (see Fig. 1(a)). The absolute value of the heat source obtained during unloading (dotted lines) is reported in order to compare it with the heat source obtained during loading. The corresponding mechanical response in terms of the stress-strain relationship is also plotted. The following comments can be made:

i. First cycle of Set $\# 1\left(\lambda_{1}=2\right)$, Figure: 3

During loading, the heat source is positive and increases with the stretch ratio. This is a major difference with respect to metallic materials, for which the heat sources due to thermoelastic coupling are constant at a fixed strain rate. During unloading, the heat source is negative. Even if the signal-to-noise ratio is too low to enable a good quantitative analysis, some additional comments can be made. It can be seen that the loadingunloading evolution is symmetrical; as a consequence, the total heat produced during loading 
is equal to the heat absorbed during unloading. In addition, this means that no mechanical dissipation is detected. Indeed, the mechanical dissipation is a positive quantity, and would lead to a positive heat over the whole cycle. This is in a good agreement with the fact that no hysteresis loop is observed in the stress-strain response.

ii. First cycle of Set \#2 $\left(\lambda_{2}=5\right)$, Figure: 4 The heat source evolutions for loading and unloading are not symmetrical. Entropic coupling is not sufficient to explain such a result. During loading, the heat source evolves in a quasi-linear manner until reaching a stretch ratio close to 4 . The corresponding curve presents a slope $S$ equal to $0.104^{\circ} \mathrm{C} / \mathrm{s}$. This evolution can be explained by entropic coupling. The fact that a dissymmetry is observed if the maximum stretch ratio applied is superior to 4 shows that the heat sources are not caused only by entropic coupling. During unloading, the heat sources are first lower than during loading (between points 3 and 2) and then higher (between points 2 and 1). Nevertheless, the area under the curves during loading and unloading is equal, meaning that no heat is produced due to mechanical dissipation. Consequently, the only explanation for the dissymmetry is the occurrence of crystallization during loading, and a difference in the kinetics of crystallization and crystallite melting (the latter during unloading). This is in a good agreement with studies reported in the literature (Toki, Fujimaki, \& Okuyama 2000). Concerning the stress-strain curve, a hysteresis loop begins to form. It is associated with the crystallization/melting phenomenon, and not with mechanical dissipation.

iii. First cycle of Set $\# 3\left(\lambda_{3}=6\right)$, Figure: 5

Similarly to the previous set, the heat source first increases with the same slope $S$ as before, and then strongly increases starting from a stretch ratio close to 4 . The loading-unloading dissymmetry of the heat source curves (when crystallization occurs) increases. From a mechanical point of view, the area of the hysteresis loop also increases. As the heat produced is equal to the heat absorbed, it can be deduced that no mechanical dissipation is detected, while the hysteresis loop continues to be observed in terms of the strain-stress relationship.

iv. First cycle of Set \#4 ( $\left.\lambda_{4}=7.5\right)$, Figure: 6

The phenomena are similar to those observed above, except the evolution of the heat source for stretch ratios superior to 6 . Indeed, during the loading phase, instead of increasing continuously, the heat source decreases from $\lambda=6$. This means that heat continues to be produced (it remains positive), but at a lower rate. This could indicate the fact that this level of stretch ratio tends to approach crystallinity saturation. It should be noted that no mechanical dissipation is detected.

In summary, mechanical cycles below the stretch ratio at which crystallization begins lead to a symmetric evolution of the heat source between loading and unloading. This accounts for entropic coupling only. Crystallization induces a strong increase in the heat source. The difference in the kinetics of crystallization and crystallite melting leads to a dissymmetry between the loading and unloading curves, and is observed in terms of heat source, but in all cases the heat produced during loading is equal to the heat absorbed during unloading. It should be noted that if no crystallization occurs, no hysteresis loop is observed for the strain-stress relationship. If the stretch ratio is superior to that at which crystallization occurs, a hysteresis loop forms (without any mechanical dissipation). This hysteresis loop is only induced by the difference in the kinetics of crystallization and crystallite melting.

\subsubsection{Relaxation test}

The heat source evolution and the nominal stress during the test are given in Figure 7. Two typical calorimetric responses are obtained:

- During loading - The heat source is always positive during the successive loading phases. If the stretch ratio is higher than $\lambda_{c}=4$ approximately, the heat source does not return to zero instantaneously when the stretch is fixed. It can be noted that, at the same time, the stress continues to decrease. Since the mechanical dissipation due to viscosity has previously been found negligible, the measured heat source is only due to thermomechanical couplings, and more especially to crystallization. It clearly appears that crystallization continues after halting the displacement of the moving grip.

- During unloading-The heat source is always negative during the successive unloading phases, and returns to zero instantaneously when the stretch ratio is maintained constant, apart from the last pause at $\lambda_{1}=2$. During the pauses at $\lambda_{2}=5, \lambda_{3}=6$ and $\lambda_{4}=7.5$, no heat source is detected from the beginning of the pause: the heat
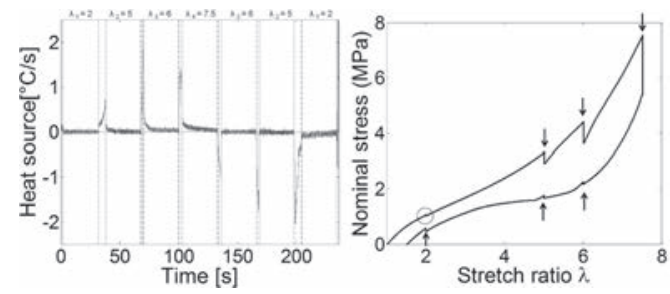

Figure 7. Relaxation test. Left: heat source versus stretch ratio. Right: strain-stress curve. 
sources return to zero instantaneously. For the last pause (at $\lambda_{1}=2$ ), the heat source does not return to zero and remains negative during the whole duration of the pause (30 seconds), as observed in Figure 7. This negative heat source, which is incompatible with mechanical dissipation, could be attributed to an additional melting process of the residual crystallites. This is an interesting result that is investigated in the next paragraph.

To study the phenomenon observed during unloading, complementary tests were performed. Compared to relaxation test, a new stage was added after the last unloading pause at $\lambda_{1}=2$ : the specimen was stretched again. Three tests were performed, with three different relaxation times at $\lambda_{1}=2: 3,30$ and $60 s$ (see Fig. 8). Each test was performed three times. The analysis focuses on rigidity at low strains $K$ measured from the strain-stress curve:

- $K_{3 s}$ measured after a relaxation time of $3 s$ (segment $\left.\left[\mathrm{b}, \mathrm{b}^{\prime}\right]\right)$;

- $K_{30 s}$ measured after a relaxation time of $30 \mathrm{~s}$ (segment [c,c']);

- $K_{60 s}$ measured after a relaxation time of $60 \mathrm{~s}$ (segment [d,d'];

- $K_{\text {initial }}$, measured on loading during stretching after the first relaxation time at $\lambda_{1}=2$ (segment $\left.\left[\mathrm{a}, \mathrm{a}^{\prime}\right]\right)$.

Figure 8 shows the nominal stress as a function of the stretch ratio. Here, only the beginning of the curve is considered, and the quantity measured is the slope of the curves. It is observed that material rigidity decreases as a function of relaxation time applied at $\lambda_{1}=2$, namely $K_{3 s}>K_{30 s}>K_{60 s}>$ $K_{\text {initial }}$. This means that the rigidity progressively returns to its lower value $K_{\text {initial }}$.

Crystallites act as supplementary reticulation points in the material network and consequently the apparent rigidity increases with crystallite concentration. Then, if the crystals melt progressively at the end of the test, the rigidity also decreases progressively as a function of time and possibly of the number of mechanical cycles (see Fig. 8). As a conclusion, crystallite melting could occur
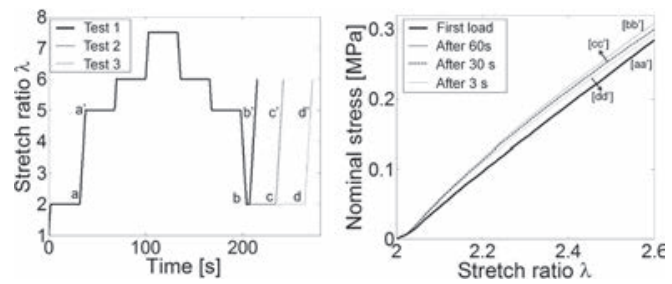

Figure 8. Complementary mechanical tests (final stretching after the relaxation phase upon unloading at $\left.\lambda_{1}=2\right)$. not instantaneously during unloading at $\lambda_{1}=2$. This could lead to a reconsideration of the physical meaning of melting by separating, for instance, (i) melting by reducing the size of the crystallites and (ii) the melting of the crystallite germs (more stable thermodynamically).

\section{CONCLUSION}

The calorimetric response of unfilled natural rubber has been characterized and interpreted during mechanical cycles and stress relaxation tests. The effects of thermomechanical couplings (entropic coupling and coupling related to crystallization/ melting) have been distinguished. Results show that:

- strain-induced crystallization leads to significant heat production whereas the melting of crystallites absorbs the same heat quantity with different kinetics;

- this difference in kinetics explains the hysteresis loop observed with respect to the strain-stress relationship, while no mechanical dissipation is detected during the deformation. Thus, a hysteresis loop in terms of the mechanical response can form without any mechanical dissipation.

- crystallite melting, classically assumed to occur instantaneously compared to crystallite formation, can be time-dependent (this is observed in the present study during unloading for a low stretch ratio). This last remark shows the relevancy of investigating the mechanism of crystallite melting.

\section{ACKNOWLEDGEMENTS}

Authors acknowledge the "Manufacture Française des pneumatiques Michelin" for supporting this study. Authors also thank D. Berghezan, F. Vion-Loisel and E. Munch for the fructuous discussions.

\section{REFERENCES}

Berthel, B., B. Wattrisse, A. Chrysochoos, \& A. Galtier (2007). Thermoelastic analysis of fatigue dissipation properties of steel sheets. Strains 43, 273-279.

Boccara, N. (1968). Les principes de la thermodynamique classique. In PUF coll. SUP.

Chrysochoos, A. (1995). Analyse du comportement des matériaux par thermographie infra rouge. In Colloque Photomécanique, Volume 95, pp. 201-211.

Chrysochoos, A. \& H. Louche (2000). An infrared image processing to analyse the calorific effects accompanying strain localisation. Int J Eng Sci 38, 1759-1788. 
Chrysochoos, A. \& H. Louche (2001). Thermal and dissipative effects accompanying luders band propagation. Mat Sci Eng A-struct 307, 15-22.

Katz, J. (1925). Naturw 4, 169.

Legorju-Jago, K. (2007, 4-7 septembre). Fatigue life of rubber components: $3 \mathrm{~d}$ damage evolution from $\mathrm{x}$-ray computed microtomography. In Constitutive Models for Rubber V-Proceedings of the Second European Conference, Paris, France, pp. 173-177.

Marchal, J. (2006). Cristallisation des caoutchoucs chargés et non chargés sous contrainte: Effet sur les chaînes amorphes. Ph. D. thesis, PhD Thesis, Université Paris XI Orsay, France.

Mullins, L. (1948). Effect of stretching on the properties of rubber. Rubber Chemistry and Technology 21, 281-300.

Nguyen, Q., P. Germain, \& P. Suquet (1983). Continuum thermodynamics. J Appl Sci 50, 1010-1020.

Pottier, T., M.-P. Moutrille, J.-B. LeCam, X. Balandraud, \& M. Grédiac (2009). Study on the use of motion compensation technique to determine heat sources. application to large deformations on cracked rubber specimens. Experimental Mechanics 49, 561-574.

Ramier, J., L. Chazeau, C. Gauthier, L. Stelandre, L. Guy, \& E. Peuvrel-Disdier (2007). In situ sals and volume variation measurements during deformation of treated silica sbr. Journal of Materials Science 42, $8130-8138$
Samaca Martinez, J. R., J.-B. Le Cam, X. Balandraud, \& E. Toussaint (2013). Mechanisms of deformation in crystallizable natural rubber. part 2: quantitative calorimetric analysis. Polymer, Doi: 10.1016/j.polymer: 2013.03.012.

Toki, S., T. Fujimaki, \& M. Okuyama (2000). Straininduced crystallization of natural rubber as detected real-time by wide-angle x-ray diffraction technique. Polymer 41, 5423-5429.

Toussaint, E., X. Balandraud, J.-B. Le Cam, \& M. Grédiac (2012). Combining displacement, strain, temperature and heat source fields to investigate the thermomechanical response of an elastomeric specimen subjected to large deformations. Polymer Testing 31, 916-925.

Trabelsi, S., P.-A. Albouy, \& J. Rault (2003). Effective local deformation in stretched filled rubber. Macromolecules 36, 9093-9099.

Wattrisse, B., A. Chrysochoos, J. Muracciole, \& M. Némoz-Gaillard (2001). Analysis of strain localization during tensile tests by digital image correlation. Experimental Mechanics 41, 29-39. 